\title{
Timing of risk reducing mastectomy in breast cancer patients carrying a $B R C A 1 / 2$ mutation: retrospective data from the Dutch HEBON study
}

\author{
M. R. Wevers • M. K. Schmidt $\cdot$ E. G. Engelhardt $\cdot$ S. Verhoef $\cdot$ M. J. Hooning \\ M. Kriege - C. Seynaeve $\cdot$ M. Collée C. J. van Asperen - R. A. E. M. Tollenaar • \\ L. B. Koppert • A. J. Witkamp • E. J. T. Rutgers • N. K. Aaronson • \\ M. A. Rookus • M. G. E. M. Ausems
}

Published online: 21 February 2015

(C) The Author(s) 2015. This article is published with open access at Springerlink.com

\begin{abstract}
It is expected that rapid genetic counseling and testing (RGCT) will lead to increasing numbers of breast cancer (BC) patients knowing their BRCA1/2 carrier status before primary surgery. Considering the potential impact of knowing one's status on uptake and timing of risk-reducing contralateral mastectomy (RRCM), we aimed to evaluate trends over time in RRCM, and differences between carriers identified either before (predictively) or after (diagnostically) diagnosis. We collected data from female BRCA1/2 mutation carriers diagnosed with $\mathrm{BC}$ between 1995 and 2009 from four Dutch university hospitals. We compared the timing of genetic testing and RRCM in relation to diagnosis in 1995-2000 versus 2001-2009 for all
\end{abstract}

Electronic supplementary material The online version of this article (doi:10.1007/s10689-015-9788-x) contains supplementary material, which is available to authorized users.

M. R. Wevers - M. K. Schmidt · E. G. Engelhardt

N. K. Aaronson · M. A. Rookus

Division of Psychosocial Research and Epidemiology, The

Netherlands Cancer Institute, PO Box 90203,

1006 BE Amsterdam, The Netherlands

e-mail: m.wevers@umcutrecht.nl

M. K. Schmidt

e-mail: mk.schmidt@nki.nl

E. G. Engelhardt

e-mail: e.m.g.engelhardt@lumc.nl

N. K. Aaronson

e-mail: n.aaronson@nki.nl

M. A. Rookus

e-mail:m.rookus@nki.nl

M. R. Wevers · M. G. E. M. Ausems ( $\square)$

Division of Biomedical Genetics, University Medical Center

Utrecht, KC.04.084.2, PO Box 85090, 3508 AB Utrecht,

The Netherlands

e-mail: m.g.e.m.ausems@umcutrecht.nl patients, and predictively and diagnostically tested patients separately. Of 287 patients, 219 (76\%) had a diagnostic BRCA1/2 test. In this cohort, the median time from diagnosis to DNA testing decreased from 28 months for those diagnosed between 1995 and 2000 to 14 months for those diagnosed between 2001 and $2009(p<0.001)$. Similarly, over time women in this cohort underwent RRCM sooner after diagnosis (median of 77 vs. 27 months, $p=0.05$ ). Predictively tested women who subsequently developed $\mathrm{BC}$ underwent an immediate RRCM significantly more often than women who had a diagnostic test $(21 / 61,34 \%$, vs. $13 / 170,7.6 \%, p<0.001)$. Knowledge of carrying a BRCA1/2 mutation when diagnosed with $\mathrm{BC}$ influenced decisions concerning primary surgery. Additionally, in more recent years, women who had not undergone predictive testing were more likely to undergo diagnostic

M. K. Schmidt

Division of Molecular Pathology, The Netherlands Cancer Institute, PO Box 90203, 1006 BE Amsterdam, The Netherlands

S. Verhoef

Family Cancer Clinic, The Netherlands Cancer Institute, PO Box 90203, 1006 BE Amsterdam, The Netherlands e-mail: s.verhoef@nki.nl

M. J. Hooning $\cdot$ M. Kriege $\cdot$ C. Seynaeve

Family Cancer Clinic, Department of Medical Oncology,

Erasmus MC Cancer Institute, PO Box 5201,

3008 AE Rotterdam, The Netherlands

e-mail: m.hooning@erasmusmc.nl

M. Kriege

e-mail: a.kriege@erasmusmc.nl

C. Seynaeve

e-mail: c.seynaeve@erasmusmc.nl 
DNA testing and RRCM sooner after diagnosis. This suggests the need for RGCT to guide treatment decisions.

Keywords $B R C A 1 \cdot B R C A 2 \cdot$ Breast neoplasms $\cdot$ Risk reducing mastectomy

\section{Introduction}

Female $B R C A 1$ or $B R C A 2$ gene mutation carriers have an increased risk of developing breast cancer of $27-88 \%$, and a maximum lifetime risk of developing ovarian cancer of $6-59 \%[1,2]$. Once diagnosed with unilateral breast cancer, BRCA1/2 mutation carriers have a $16-55 \%$ risk of developing contralateral breast cancer within 25 years, depending on, among other factors, age at first diagnosis and the mutated gene $[3,4]$.

In the case of a favorable disease stage and prognosis, mutation carriers diagnosed with breast cancer may opt for a risk reducing contralateral mastectomy (RRCM), which reduces the risk of contralateral breast cancer by more than $90 \%$, with increasing evidence of improved breast cancer specific survival [5-9]. The reported uptake of RRCM in such women ranges from 18 to $65 \%$ [10-13]. The period of follow-up in these studies varied between a few months to several years after genetic test disclosure or breast cancer diagnosis.

Genetic testing of the BRCAl/2 genes became available from 1994 onwards. In current practice, breast cancer patients at risk of having hereditary cancer are typically referred for genetic counseling and diagnostic DNA testing after their primary treatment [14-17]. In such cases, affected carriers may consider undergoing a delayed RRCM [18]. Unaffected women who become aware of their carrier status via a predictive DNA test (i.e. while still asymptomatic) and subsequently develop breast cancer, may consider an immediate RRCM (i.e. at the time of the therapeutic surgery).

However, genetic counseling and testing (GCT) can also be offered to high-risk women between breast cancer

\footnotetext{
M. Collée

Department of Clinical Genetics, Erasmus University Medical Center, PO Box 2040, 3000 CA Rotterdam, The Netherlands e-mail: j.collee@erasmusmc.nl

C. J. van Asperen

Department of Clinical Genetics, Leiden University Medical

Center, PO Box 9600, 2300 RC Leiden, The Netherlands

e-mail: asperen@lumc.nl

R. A. E. M. Tollenaar

Division of Surgery, Leiden University Medical Center,

PO Box 9600, 2300 RC Leiden, The Netherlands

e-mail: r.a.e.m.tollenaar@lumc.nl
}

diagnosis and primary surgical treatment (rapid genetic counseling and testing, or RGCT). Being aware of one's carrier status may influence treatment decisions, including type of surgery, use of adjuvant radiotherapy and whether to undergo an immediate RRCM [19-21]. Such knowledge may be particularly important for high risk women who are determined not to carry a BRCAl/2 mutation, as their risk of developing contralateral breast cancer may be substantially lower than initially suspected [4, 22, 23].

It is expected that RGCT will become widely available in the near future. Information on uptake and timing of prophylactic measures chosen by carriers diagnosed with breast cancer with a favorable prognosis is therefore increasingly relevant. Such information can help breast cancer specialists to better understand the place of genetic testing in the clinical pathway of breast cancer diagnosis and treatment, and ultimately can contribute to optimal multidisciplinary treatment and care of women with breast cancer [13, 22, 24].

The objective of the current study was to describe trends over the years 1995-2009 in the timing of genetic testing and of prophylactic mastectomy in breast cancer patients carrying a BRCA1/2 mutation. More specifically, our aims were to describe (1) the timing of genetic testing in relation to breast cancer diagnosis; (2) the uptake of immediate RRCM (i.e., at the time of breast cancer surgical therapy) and of delayed RRCM; and (3) the timing of RRCM in relation to diagnosis.

\section{Materials and methods}

\section{Study population}

The Dutch HEBON study (Hereditary Breast and Ovarian cancer study, the Netherlands) is a retrospective cohort study of members of families with a BRCA1 or BRCA2 mutation from 1994 onwards, with a prospective follow-up [25]. The HEBON study was approved by the medical ethical committees of all centers that recruited patients, and

\section{B. Koppert}

Division of Surgery, Erasmus MC Cancer Institute, PO Box 5201, 3008 EA Rotterdam, The Netherlands e-mail: 1.koppert@erasmusmc.nl

\section{A. J. Witkamp}

Division of Surgery, University Medical Center Utrecht, PO Box 85500, 3508 GA Utrecht, The Netherlands e-mail: a.j.witkamp@umcutrecht.nl

\section{E. J. T. Rutgers}

Division of Surgery, The Netherlands Cancer Institute, PO Box 90203, 1006 BE Amsterdam, The Netherlands e-mail: e.rutgers@nki.nl 
all individuals provided informed consent. The database includes information on DNA test results, occurrence of cancer, treatment, and risk-reducing surgery. BRCA1/2 mutation testing could be performed before (i.e., predictive) or after breast cancer diagnosis (i.e., diagnostic) (supplementary Figure 1). Within the HEBON-database, data on tumor characteristics and treatment were available for a subset of 329 female BRCA1/2 mutation carriers who were diagnosed with breast cancer (both in situ and invasive) from 1995 onwards and were treated in the Erasmus University Medical Center (Erasmus MC) Cancer Institute, the Netherlands Cancer Institute (NKI), the University Medical Center Utrecht (UMCU) or the Leiden University Medical Center (LUMC), and were counseled in the departments of clinical genetics in those hospitals. Of those 329 carriers, 287 women had no distant metastases and/or other type(s) of cancer at time of breast cancer diagnosis, were a proven $B R C A 1 / 2$ mutation carrier, had date of DNA test result available, and had type of breast cancer surgery available, and could therefore be included in the study.

\section{Exclusion criteria for choice of RRCM}

For questions concerning choice of immediate RRCM, exclusion criteria were: (e) synchronous bilateral breast cancer; and (f) breast cancer after a prophylactic bilateral mastectomy; together $\mathrm{n}=56$. For questions concerning choice of delayed RRCM, additional exclusion criteria were: (g) diagnosis of (metastases of) other type(s) of cancer at time of DNA test result; (h) having received treatment and counseling in the LUMC due to too many missing data on prophylactic mastectomy; (i) missing data on RRCM; and (j) having had a RRCM before contralateral breast cancer diagnosis, i.e., being diagnosed with breast cancer despite having undergone a RRCM; together $\mathrm{n}=80$. A contralateral mastectomy without information whether it was prophylactic or therapeutic was considered a $\operatorname{RRCM}(\mathrm{n}=1)$.

An immediate RRCM is defined as removal of the contralateral breast at the same date as the therapeutic mastectomy. Delayed RRCM is defined as removal of the contralateral breast at some time after the primary surgery. In case of a prior breast conserving surgery, the ipsilateral breast is removed as well.

\section{Data collection}

For the current study, the following data were retrieved from the HEBON-database: date of birth; tumor characteristics [ductal carcinoma in situ (DCIS) or invasive breast cancer, TNM stage, unilateral or bilateral breast cancer, date of diagnosis]; history of other cancers; mutated gene (BRCA1 or BRCA2); date of DNA test result; type of surgical treatment for breast cancer; date(s) of breast cancer surgery/surgeries; type(s) and date(s) of prophylactic breast surgery/surgeries; and hospital where treatment and DNA-testing were performed. Tumor stage was categorized according to the TNM classification as included in the breast cancer guideline 2.0 (2012) of the Comprehensive Cancer Center the Netherlands [16].

\section{Statistical analyses}

Chi square tests were used to compare choice of immediate and delayed RRCM for women who underwent a predictive DNA test versus those who had a diagnostic test, for women who were treated in 1995-2000 versus 2001-2009 separately. We chose to analyze these two time periods because, from 2001 onwards, in the Netherlands increased awareness among breast cancer specialists and probably also patients had led to larger numbers of breast cancer patients being referred for genetic counseling and testing, and GCT had become more conventional. With this division, the number of patients in both time periods still is relatively well distributed. Mann-Whitney U tests were used to compare time between breast cancer diagnosis and DNA testing for the time periods 1995-2000 versus 2001-2009. Kaplan-Meier analyses were used to compare time between first breast cancer diagnosis and risk reducing surgery, and between DNA test result and delayed risk reducing surgery for the time periods 1995-2000 versus 2001-2009. End of time under follow-up was defined as either RRCM, contralateral breast cancer diagnosis, or end of follow-up, whatever came first. Patients who had a predictive test and those who had a diagnostic test were analyzed separately, when applicable.

In addition, Cox regression was used to compare the time between diagnosis and RRCM for both time periods (categorical 1995-2000 vs. 2001-2009) adjusted for age at diagnosis (continuous variable in years), predictive versus diagnostic testing (categorical variable), nodal status (categorical positive vs. negative), and use of chemotherapy (categorical yes vs. no). Patients who had a predictive test and those who had a diagnostic test were also analyzed separately.

\section{Results}

Clinical and sociodemographic characteristics of the sample

From the HEBON subset of 329 women who were diagnosed with breast cancer between 1995 and 2009 in one of the participating hospitals, we included 287 BRCAl/2 mutation carriers. The majority of the patients (77 \%) had a BRCA1 mutation (Table 1). 


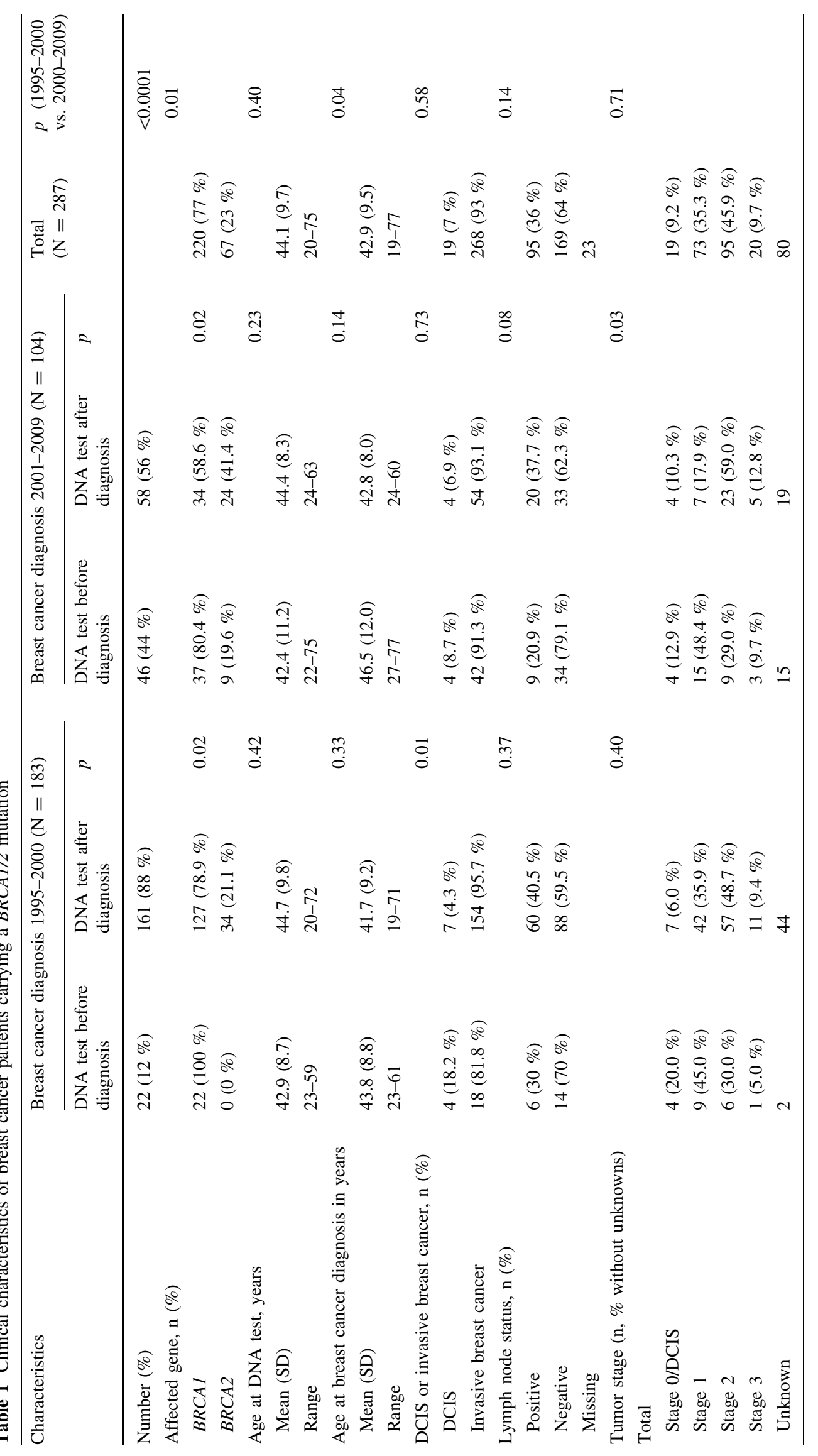


One hundred eighty-three $B R C A 1 / 2$ mutation carriers (64\%) were diagnosed with breast cancer between 1995 and 2000, and 104 (36 \%) between 2001 and 2009. Mean age at breast cancer diagnosis was 42.0 years for patients diagnosed between 1995 and 2000, compared to 44.4 years for those diagnosed between 2001 and $2009(p=0.04)$. Other sample characteristics are described in Table 1. Of note, exclusion of DCIS cases did not alter significantly any of the findings presented in this paper (data not shown).

\section{Timing of genetic counseling and testing (GCT)}

Of all patients, 219 (76\%) had a diagnostic DNA test and $68(24 \%)$ had a predictive DNA test. Of those who had a diagnostic test, 4 received their DNA test results before primary surgery (i.e., had RGCT). Predictive DNA testing increased from $12 \%$ for those diagnosed between 1995 and 2000 to $44 \%$ for those diagnosed between 2001 and $2009(p<0.001)$ (Table 1). For patients who had a diagnostic test, the median time between breast cancer diagnosis and DNA test result decreased from 28 months [range 0-143; mean (SD) 35.7 (31.2)] for patients diagnosed between 1995 and 2000 to 14 months [range 0-80, mean (SD) 18.8 (16.5)] for those diagnosed between 2001 and $2009(p<0.001)$.

\section{Uptake of risk reducing mastectomy}

Immediate risk reducing contralateral mastectomy at the time of breast cancer surgery Of the 231 patients for whom these data were available, $34(14.7 \%)$ had an immediate RRCM (Table 2 and supplementary flowchart). Considering the complete time period 1995-2009, breast cancer patients who had a predictive test opted for an immediate RRCM significantly more often than patients who had a diagnostic test (34.4 vs. $7.6 \%, p<0.001)$; this difference was seen in the time period 1995-2000 as well as in 2001-2009 (Table 2). Within the subgroup of predictively tested patients who underwent an immediate RRCM, there was no significant difference $(p=0.23)$ observed in choice of immediate RRCM between 1995 and 2000 (9/20, 45.0 \%) versus 2001-2009 (12/41, $29.3 \%)$.

Delayed risk reducing contralateral mastectomy after completion of primary breast cancer therapy Of the 151 patients from the NKI, UMCU and Erasmus MC for whom relevant data were available, $73(48.3 \%)$ had a delayed RRCM after breast cancer diagnosis (Table 2). The uptake of a delayed RRCM was not significantly different between patients who had a predictive DNA test and those who had a diagnostic DNA test in neither of the time periods (Table 2). However, within the subgroup of patients who had a diag-

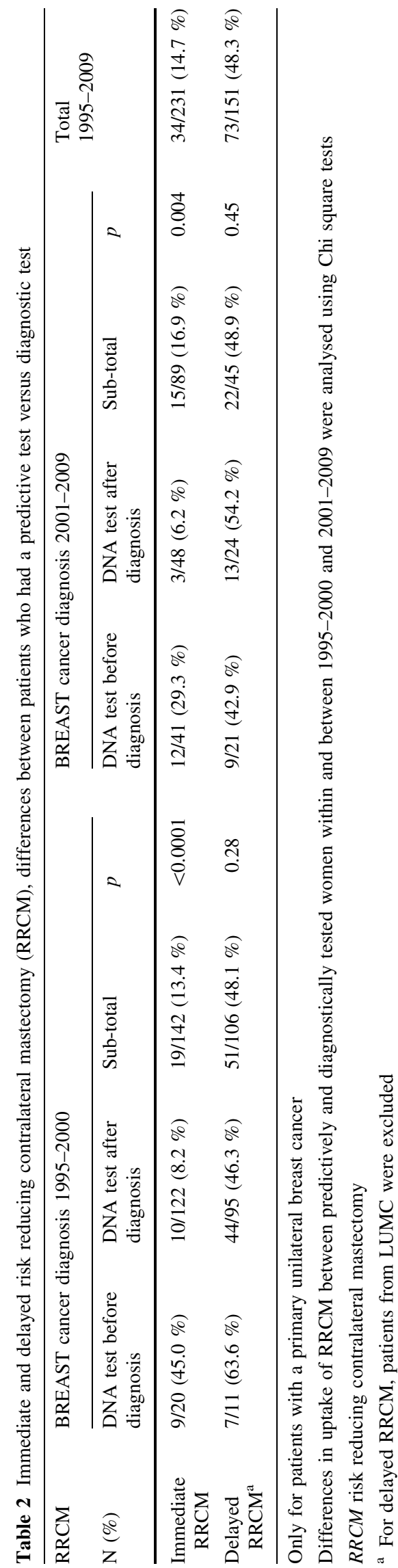


nostic test, patients who received DNA test results within a year after BC diagnosis opted for a delayed RRCM significantly more often than patients who received DNA test results more than a year after BC diagnosis [26/37 (70.3\%) versus $31 / 82(37.8 \%), p=0.001]$. This difference was also seen in the separate time periods $[16 / 24(66.7 \%)$ versus $28 / 71(39.4 \%), p=0.02$ in $1995-2000$, and 10/13 (76.9\%) versus $3 / 11(27.3 \%), p=0.02$ in 2001-2009].

\section{Timing of risk reducing contralateral mastectomy}

Overall, $50.5 \%$ of patients who were diagnosed between 1995 and 2000 had an immediate or delayed RRCM within 5 years since breast cancer diagnosis, compared with $68.1 \%$ for patients diagnosed between 2001 and 2009 (Fig. 1a). However, there was an indication for a difference between predictively and diagnostically tested patients, with a decrease of $80.0-69.5 \%$ in patients who had a predictive test (Fig. 1b), and an increase of 44.7-65.4\% in patients who had a diagnostic test (Fig. 1c). In the Cox analyses, adjusted for age at diagnosis, nodal status and chemotherapy, of those diagnosed in 2001-2009, predictively tested patients were less likely, and diagnostically tested patients were more likely, to have had a RRCM than those diagnosed in 1995-2000, although both differences were not significant (Table 3 ). In the same multivariate model, older patients who had a predictive test were less likely to undergo a RRCM than younger patients who had a predictive test (HR 0.95, $95 \%$ CI 0.92-0.99, $p=0.01$ ).

In the Cox analyses for predictively and diagnostically tested patients together, adjusted for age at diagnosis, time period of diagnosis, nodal status and chemotherapy, patients who had a predictive test were more likely to have had a RRCM than patients who had a diagnostic test, with a hazard ratio of 4.49 (95 \% CI 2.5-8.1, $p<0.001)$. In addition, older patients were again less likely to undergo a RRCM than younger patients; but only significantly so if they had a predictive test (HR 0.96, 95 \% CI 0.94-0.98, $0<0.001$ ).

For diagnostically tested patients, the mean time between DNA test results and delayed RRCM decreased over time from 108.8 months (SD 5.1) in 1995-2000 to 67.3 months in 2001-2009 (SD 5.9, $p<0.001$ ) (Fig. 1d). There was an increase in the percentage of patients who had a RRCM 5 years after DNA test result from 17.5 to $37.5 \%$.

\section{Discussion}

Our data show that, in the time period 2001-2009, BRCAl/ 2 mutation carriers who were not aware of their carrier status at the time of their breast cancer diagnosis, had diagnostic DNA testing sooner after diagnosis than those in the time period 1995-2000. Additionally, the proportion of breast cancer patients who had predictive DNA testing increased significantly over time. This shift towards more predictive testing probably reflects the greater availability, completeness and acceptance of DNA testing over time, and a decrease in the time required to report test results. However, a survival bias cannot be ruled out, as patients must have survived long enough to be recruited in the HEBON study. Importantly, our data also clearly indicate that women known to be carrier before breast cancer diagnosis opted significantly more often for an immediate RRCM than those who had a DNA test after cancer diagnosis. Apparently, for the decision to undergo an immediate RRCM, DNA test results are more important to both patients and treating specialists than being at risk of having hereditary breast cancer only. This is relevant, since there are concerns that RGCT will increase the percentage of women opting for an immediate RRCM not only in carriers, but also in women without a pathogenic mutation. However, this finding suggests that it is unlikely for RGCT to make women without a mutation opt more often for an immediate RRCM. There was, however, no significant increase over time in the frequency of RRCM in patients who had a predictive test. Similarly, no trend over time was seen for the uptake of delayed RRCM in both patients who had a predictive test and those who had a diagnostic test. Patients who had a diagnostic test opted for RRCM sooner after breast cancer diagnosis in the more recent time period.

Overall, $34 \%$ of the patients who developed unilateral breast cancer after a predictive DNA test had an immediate RRCM. This is only slightly less than the percentage reported by Cortesi et al.[19], who observed that $42 \%$ of women who became aware of their carrier status within 1 month after breast cancer diagnosis opted for a RRCM, although it is not clear whether this was performed at the time of primary surgery or thereafter. As to our knowledge, no other studies provide explicit information on the timing of DNA testing (i.e., predictive or diagnostic), which makes it difficult to compare results. However, two American studies provide some information. King et al. [26] observed that $54 \%$ of affected carriers had a RRCM within 1 year after diagnosis. Chung et al. observed that $13 / 16(81 \%)$ of women diagnosed with breast cancer between 1995 and 2008 who were BRCA1/2 mutation carriers, had an immediate RRCM. Contrary to our findings, they observed an increase in the frequency of immediate RRCM over time, in both mutation carriers and in women without (knowledge of) a BRCA1/2 mutation [27]. The increase in RRCMs over time appears to be more common in the United States, and particularly in women without an increased risk of contralateral breast cancer [26, 28-30].

In line with data from an earlier study [12], $48 \%$ of affected carriers in our study had a delayed RRCM. 

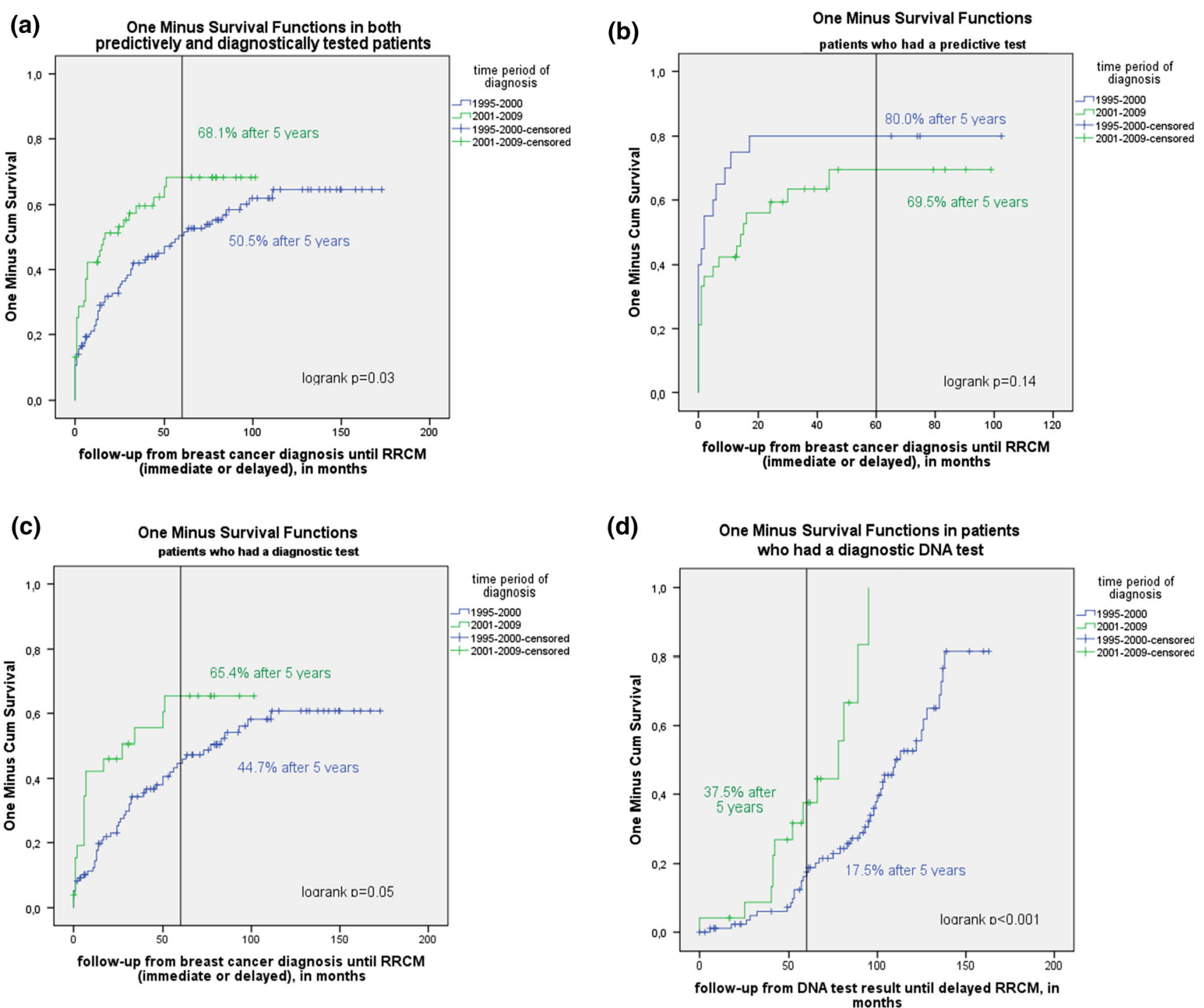

Fig. 1 Kaplan Meier curves of cumulative RRCM incidence a Cumulative RRCM (immediate or delayed) incidence from time of breast cancer diagnosis comparing two time periods in both predictively and diagnostically tested patients b Cumulative RRCM (immediate or delayed) incidence from time of breast cancer diagnosis comparing two time periods in patients who had a

Interestingly, patients who had a diagnostic DNA test and a delayed RRCM tended to opt for this surgery sooner after breast cancer diagnosis in the more recent time period (from a median of 77-27 months). This may be explained, at least in part, by the fact that the time between breast cancer diagnosis and DNA test results decreased in this group from 28 months in patients diagnosed 1995-2000 to 14 months in patients diagnosed 2001-2009. It is unclear whether this reflects primarily an earlier decision to undergo RRCM, reduced waiting times for surgery or differences in advice from the multidisciplinary team.

Our study had several limitations that should be noted. Women treated for breast cancer in 1995-2000 differed

predictive test c Cumulative RRCM (immediate or delayed) incidence from time of breast cancer diagnosis comparing two time periods in patients who had a diagnostic test $\mathbf{d}$ Cumulative delayed RRCM incidence from time of DNA test result in patients who had a diagnostic test. *RRCM risk reducing contralateral mastectomy

from those treated in 2001-2009 in age at diagnosis, follow-up time, and possibly also were subject to survival bias. Second, our sample with data available on risk reducing mastectomy was rather small. Third, although there may have been between-hospital variation in the criteria used for performing a RRCM (e.g., disease-free time since diagnosis or nodal status), use of MRI at breast cancer diagnosis, or availability and quality of breast reconstruction, we did not have data to address this question. Finally, we analyzed BRCA1 and BRCA2 mutation carriers together, also in view of the small numbers of $B R C A 2 \mathrm{mu}-$ tation carriers. However, we do not expect significant differences between $B R C A 1$ and $B R C A 2$ mutation carriers 
Table 3 Timing of risk reducing contralateral mastectomy (RRCM) in women with $B R C A$-associated breast cancer

\begin{tabular}{|c|c|c|c|c|c|c|}
\hline \multirow[t]{2}{*}{ RRCM after breast cancer diagnosis } & \multicolumn{3}{|c|}{$\begin{array}{l}\text { Breast cancer patients who had a DNA test before } \\
\text { diagnosis (predictive) }(n=53)\end{array}$} & \multicolumn{3}{|c|}{$\begin{array}{l}\text { Breast cancer patients who had a DNA test after } \\
\text { diagnosis (diagnostic) }(n=127)\end{array}$} \\
\hline & $\begin{array}{l}\text { Breast cancer } \\
\text { diagnosis } \\
\text { 1995-2000 }\end{array}$ & $\begin{array}{l}\text { Breast cancer } \\
\text { diagnosis } \\
2001-2009\end{array}$ & $p$ & $\begin{array}{l}\text { Breast cancer } \\
\text { diagnosis } \\
1995-2000\end{array}$ & $\begin{array}{l}\text { Breast cancer } \\
\text { diagnosis } \\
2001-2009\end{array}$ & $p$ \\
\hline Age at RRCM in years & & & 0.62 & & & 0.55 \\
\hline Mean (SD) & $42.1(7.9)$ & $44.2(10.0)$ & & $41.8(7.8)$ & $40.3(7.7)$ & \\
\hline Median (range) & $41.5(25-53)$ & $45.0(27-71)$ & & $41.0(22-62)$ & $40.5(25-54)$ & \\
\hline $\begin{array}{l}\text { Median time in months between } \\
\text { diagnosis and } \text { RRCM }^{\mathrm{a}}\end{array}$ & 2 & 15 & 0.14 & 77 & 27 & 0.05 \\
\hline $\begin{array}{l}\text { RRCM 2001-2009 versus } 1995-2000 \\
\text { HR }(95 \% \text { CI })^{\mathrm{b}}\end{array}$ & $0.73(0.36-1.48)$ & & & $1.72(0.91-3.27)$ & & \\
\hline
\end{tabular}

Only for patients with information on whether having undergone RRCM (from Erasmus MC Cancer Institute, NKI and UMCU), who had unilateral breast cancer. Immediate and delayed RRCM were analyzed together

$R R C M$ risk reducing contralateral mastectomy

${ }^{\text {a }}$ Kaplan-Meier analyses for predictive and diagnostic patients

b Separate Cox regression models for predictive and diagnostic patients, adjusted for age at diagnosis, nodal status, and chemotherapy

in choice of (risk reducing) breast surgery, since both groups probably received similar information about the risk of (contralateral) breast cancer.

Our study also has a number of noteworthy strengths. First, unlike most earlier studies, we have reported results on the choice of RRCM separately for mutation carriers who developed breast cancer following a predictive DNA test, and those mutation carriers who had a diagnostic DNA test following their breast cancer diagnosis. Second, we investigated trends over time; something that was not done in some earlier, large studies of risk reducing surgery in $B R C A 1 / 2$ mutation carriers with breast cancer $[10,11,31]$.

Implications for daily practice

Our results indicate that knowledge of one's carrier status at the time of breast cancer diagnosis is important in decisions about risk reducing mastectomy, and that for those without this knowledge, especially in young breast cancer patients, there may be a need for RGCT to guide treatment decisions.

Since the use of neo-adjuvant chemotherapy is increasing, it is expected that an increasing number of patients will be able to receive DNA test results before primary surgery and incorporate these in their treatment decisions. With such information at hand, both breast cancer specialists and their high-risk breast cancer patients will hopefully be able to make more informed decisions about the most appropriate, individualized treatment.

Acknowledgments The HEBON study is supported by the Dutch Cancer Society Grants NKI1998-1854, NKI2004-3088, NKI20073756, the Netherlands Organization of Scientific Research grant NWO 91109024, the Pink Ribbon Grant 110005 and the BBMRI grant NWO 184.021.007/CP46. For this specific study question further funding was received from the department of Medical Genetics, from of the University Medical Center Utrecht, the Netherlands.

Conflict of interest The authors declare that they have no conflict of interest.

Open Access This article is distributed under the terms of the Creative Commons Attribution License which permits any use, distribution, and reproduction in any medium, provided the original author(s) and the source are credited.

\section{References}

1. van der Kolk DM, de Bock GH, Leegte BK, Schaapveld M, Mourits MJ, de Vries J, van der Hout AH, Oosterwijk JC (2010) Penetrance of breast cancer, ovarian cancer and contralateral breast cancer in BRCA1 and BRCA2 families: high cancer incidence at older age. Breast Cancer Res Treat 124(3):643-651

2. Brohet RM, Velthuizen ME, Hogervorst FB, Ej Meijers-Heijboer H, Seynaeve C, Collee MJ, Verhoef S, Ausems MG, Hoogerbrugge N, van Asperen CJ, Gomez GE, Menko F, Oosterwijk JC, Devilee P, Veer LJ, van Leeuwen FE, Easton DF, Rookus MA, Antoniou AC (2014) Breast and ovarian cancer risks in a large series of clinically ascertained families with a high proportion of BRCA1 and BRCA2 Dutch founder mutations. J Med Genet 51(2):98-107

3. Metcalfe K, Gershman S, Lynch HT, Ghadirian P, Tung N, KimSing C, Olopade OI, Domchek S, McLennan J, Eisen A, Foulkes WD, Rosen B, Sun P, Narod SA (2011) Predictors of contralateral breast cancer in BRCA1 and BRCA2 mutation carriers. Br J Cancer 104(9):1384-1392

4. Rhiem K, Engel C, Graeser M, Zachariae S, Kast K, Kiechle M, Ditsch N, Janni W, Mundhenke C, Golatta M, Varga D, PreislerAdams S, Heinrich T, Bick U, Gadzicki D, Briest S, Meindl A, Schmutzler RK (2012) The risk of contralateral breast cancer in patients from BRCA1/2 negative high risk families as compared to patients from BRCA1 or BRCA2 positive families: a retrospective cohort study. Breast Cancer Res 14(6):R156 
5. van Sprundel TC, Schmidt MK, Rookus MA, Brohet R, van Asperen CJ, Rutgers EJ, Van't Veer LJ, Tollenaar RA (2005) Risk reduction of contralateral breast cancer and survival after contralateral prophylactic mastectomy in BRCA1 or BRCA2 mutation carriers. Br J Cancer 93(3):287-292

6. Lostumbo L, Carbine NE, and Wallace J (2010) Prophylactic mastectomy for the prevention of breast cancer. Cochrane Database Syst Rev 11:CD002748

7. Domchek SM, Friebel TM, Singer CF, Evans DG, Lynch HT, Isaacs C, Garber JE, Neuhausen SL, Matloff E, Eeles R, Pichert G, Van t'veer L, Tung N, Weitzel JN, Couch FJ, Rubinstein WS, Ganz PA, Daly MB, Olopade OI, Tomlinson G, Schildkraut J, Blum JL, Rebbeck TR (2010) Association of risk-reducing surgery in BRCA1 or BRCA2 mutation carriers with cancer risk and mortality. JAMA 304(9):967-975

8. Metcalfe K, Gershman S, Ghadirian P, Lynch HT, Snyder C, Tung N, Kim-Sing C, Eisen A, Foulkes WD, Rosen B, Sun P, Narod SA (2014) Contralateral mastectomy and survival after breast cancer in carriers of BRCA1 and BRCA2 mutations: retrospective analysis. BMJ 348:g226

9. Evans DG, Ingham SL, Baildam A, Ross GL, Lalloo F, Buchan I, Howell A (2013) Contralateral mastectomy improves survival in women with BRCA1/2-associated breast cancer. Breast Cancer Res Treat 140(1):135-142

10. Metcalfe KA, Lubinski J, Ghadirian P, Lynch H, Kim-Sing C, Friedman E, Foulkes WD, Domchek S, Ainsworth P, Isaacs C, Tung N, Gronwald J, Cummings S, Wagner T, Manoukian S, Moller P, Weitzel J, Sun P, Narod SA (2008) Predictors of contralateral prophylactic mastectomy in women with a BRCA1 or BRCA2 mutation: the Hereditary Breast Cancer Clinical Study Group. J Clin Oncol 26(7):1093-1097

11. Graves KD, Peshkin BN, Halbert CH, DeMarco TA, Isaacs C, Schwartz MD (2007) Predictors and outcomes of contralateral prophylactic mastectomy among breast cancer survivors. Breast Cancer Res Treat 104(3):321-329

12. Evans DG, Lalloo F, Hopwood P, Maurice A, Baildam A, Brain A, Barr L, Howell A (2005) Surgical decisions made by 158 women with hereditary breast cancer aged $<50$ years. Eur J Surg Oncol 31(10): 1112-1118

13. Howard AF, Bottorff JL, Balneaves LG, Kim-Sing C (2010) Women's constructions of the 'right time' to consider decisions about risk-reducing mastectomy and risk-reducing oophorectomy. BMC Womens Health 10:24

14. The National Breast cancer Organisation the Netherlands (NABON) and Comprehensive Cancer Center the Netherlands (VIKC). The National Breast cancer Organisation the Netherlands (NABON) - Breast Cancer Guideline 2.0. http://www. oncoline.nl/index.php?pagina=/richtlijn/item/pagina.php\&richtlijn_ id $=608.2008$

15. The Netherlands Foundation for the Detection of Hereditary Tumours (STOET) and the Dutch Society of Clinical Genetics (VKGN) (2010) Erfelijke tumoren: richtijnen voor diagnostiek en preventie, 4 edn

16. Comprehensive Cancer Center the Netherlands (IKNL). Breast cancer guideline 2.0. www.oncoline.nl/mammacarcinoom. 2013

17. van Riel E, Warlam-Rodenhuis CC, Verhoef S, Rutgers EJ, Ausems MG (2010) BRCA testing of breast cancer patients: medical specialists' referral patterns, knowledge and attitudes to genetic testing. Eur J Cancer Care (Engl) 19(3):369-376

18. Watts KJ, Meiser B, Mitchell G, Kirk J, Saunders C, Peate M, Duffy J, Kelly PJ, Gleeson M, Barlow-Stewart K, Rahman B, Friedlander M, Tucker K (2012) How should we discuss genetic testing with women newly diagnosed with breast cancer? Design and implementation of a randomized controlled trial of two models of delivering education about treatment-focused genetic testing to younger women newly diagnosed with breast cancer. BMC Cancer 12:320

19. Cortesi L, Razzaboni E, Toss A, De ME, Marchi I, Medici V, Tazzioli G, Andreotti A, De SG, Pignatti M, Federico M (2014) A rapid genetic counselling and testing in newly diagnosed breast cancer is associated with high rate of risk-reducing mastectomy in BRCA1/2-positive Italian women. Ann Oncol 25(1):57-63

20. Meiser B, Tucker K, Friedlander M, Barlow-Stewart K, Lobb E, Saunders C, Mitchell G (2008) Genetic counselling and testing for inherited gene mutations in newly diagnosed patients with breast cancer: a review of the existing literature and a proposed research agenda. Breast Cancer Res 10(6):216

21. Wevers MR, Ausems MG, Verhoef S, Bleiker EM, Hahn DE, Hogervorst FB, van der Luijt RB, Valdimarsdottir HB, van Hillegersberg R, Rutgers EJ, Aaronson NK (2011) Behavioral and psychosocial effects of rapid genetic counseling and testing in newly diagnosed breast cancer patients: design of a multicenter randomized clinical trial. BMC Cancer 11:6

22. Mai PL, Lagos VI, Palomares MR, Weitzel JN (2008) Contralateral risk-reducing mastectomy in young breast cancer patients with and without genetic cancer risk assessment. Ann Surg Oncol 15(12):3415-3421

23. Reiner AS, John EM, Brooks JD, Lynch CF, Bernstein L, Mellemkjaer L, Malone KE, Knight JA, Capanu M, Teraoka SN, Concannon P, Liang X, Figueiredo JC, Smith SA, Stovall M, Pike MC, Haile RW, Thomas DC, Begg CB, Bernstein JL (2013) Risk of asynchronous contralateral breast cancer in noncarriers of BRCA1 and BRCA2 mutations with a family history of breast cancer: a report from the Women's Environmental Cancer and Radiation Epidemiology Study. J Clin Oncol 31(4):433-439

24. Beattie MS, Crawford B, Lin F, Vittinghoff E, Ziegler J (2009) Uptake, time course, and predictors of risk-reducing surgeries in BRCA carriers. Genet Test Mol Biomarkers 13(1):51-56

25. Pijpe A, Manders P, Brohet RM, Collee JM, Verhoef S, Vasen $\mathrm{HF}$, Hoogerbrugge N, van Asperen CJ, Dommering C, Ausems MG, Aalfs CM, Gomez-Garcia EB, Van't Veer LJ, van Leeuwen FE, Rookus MA (2010) Physical activity and the risk of breast cancer in BRCA1/2 mutation carriers. Breast Cancer Res Treat 120(1):235-244

26. King TA, Sakr R, Patil S, Gurevich I, Stempel M, Sampson M, Morrow M (2011) Clinical management factors contribute to the decision for contralateral prophylactic mastectomy. J Clin Oncol 29(16):2158-2164

27. Chung A, Huynh K, Lawrence C, Sim MS, Giuliano A (2012) Comparison of patient characteristics and outcomes of contralateral prophylactic mastectomy and unilateral total mastectomy in breast cancer patients. Ann Surg Oncol 19(8):2600-2606

28. Howard-McNatt M, Schroll RW, Hurt GJ, Levine EA (2011) Contralateral prophylactic mastectomy in breast cancer patients who test negative for BRCA mutations. Am J Surg 202(3):298-302

29. Stucky CC, Gray RJ, Wasif N, Dueck AC, Pockaj BA (2010) Increase in contralateral prophylactic mastectomy: echoes of a bygone era? Surgical trends for unilateral breast cancer. Ann Surg Oncol 17(Suppl 3):330-337

30. Murphy JA, Milner TD, O’Donoghue JM (2013) Contralateral risk-reducing mastectomy in sporadic breast cancer. Lancet Oncol 14(7):e262-e269

31. Kiely BE, Jenkins MA, McKinley JM, Friedlander ML, Weideman P, Milne RL, McLachlan SA, Hopper JL, Phillips KA (2010) Contralateral risk-reducing mastectomy in BRCA1 and BRCA2 mutation carriers and other high-risk women in the Kathleen Cuningham Foundation Consortium for Research into Familial Breast Cancer (kConFab). Breast Cancer Res Treat 120(3):715-723 